\title{
Damage Limited to the Hippocampal Region Produces Long- Lasting Memory Impairment in Monkeys
}

\author{
Pablo Alvarez, ${ }^{1}$ Stuart Zola-Morgan, ${ }^{1,2,4}$ and Larry R. Squire ${ }^{1,2,3,4}$ \\ 'Group in Neurosciences and Departments of ${ }^{2}$ Psychiatry and ${ }^{3}$ Neuroscience, University of California at San Diego, \\ La Jolla, California 92093, and ${ }^{4}$ Veterans Affairs Medical Center, San Diego, California 92161
}

Research In humans and monkeys has demonstrated a system of anatomically related structures in the medial temporal lobe that is important for memory function. This system is comprised of the hippocampal region (i.e., the dentate gyrus, hippocampus proper and subicular complex) and the entorhinal, perirhinal, and parahippocampal cortices. While the hippocampal region has long been thought to be important in memory, there are few systematic studies in primates of the effects on memory of damage limited to the hippocampal region. We have used magnetic resonance imaging techniques, together with a stereotaxic approach, to produce bilateral lesions limited to the hippocampal region (the $\mathrm{H}$ lesion). Damage to the adjacent perirhinal, entorhinal, and parahippocampal cortex was minimal. Monkeys with the $\mathrm{H}$ lesion exhibited significant and long-lasting impairment on the delayed nonmatching to sample task. At the same time, on this and other amnesia-sensitive tasks, monkeys with the $\mathrm{H}$ lesion performed better overall than monkeys with lesions of the hippocampal region that also included damage to the adjacent entorhinal and parahippocampal cortices (the $\mathrm{H}^{+} \mathrm{le}-$ sion). These findings show that, first, the hippocampal region itself is essential for normal memory function; and second, the adjacent entorhinal and parahippocampal cortices, either alone or in combination, are also an essential component of the medial temporal lobe memory system.

[Key words: memory, amnesia, monkey, hippocampus, dentate gyrus, subiculum, entorhinal cortex, amygdala, delayed nonmatching to sample task]

Work in monkeys completed in the last decade (for reviews, Squire and Zola-Morgan, 1991; Zola-Morgan and Squire, 1993; also Meunier et al., 1993; Zola-Morgan et al., 1993) has identified a neural system important for memory in the medial tem-

Received June 6, 1994; revised Nov, 30, 1994; accepted Dec. 7, 1994

This work was supported by the Medical Rescarch Scrvice of the Department of Veterans Affairs, NIH Grant 19063, the Office of Naval Research and a McDonnell-Pew graduate fellowship in Cognitive Neuroscience (to P.A.). We thank D. G. Amaral for helpful discussions and R. P. Clower for assisting in the development of the surgical procedure used for making the lesions in the hippocampal region. We also thank C. M. LeClair and A. K. Lockwood for behavioral testing and technical assistance and $S$. Ramus and $N$. Rempel for assistance in histological processing and analysis of the brain tissue. A research protocol describing all aspects of the present study that related to the use of animals (care and maintenance, surgery, behavioral testing, and euthanasia) was approved by the Animal Research Committees of the V.A. Medical Center, San Diego, and the University of California at San Diego.

Correspondence should be addressed to Stuart Zola-Morgan, Department of Psychiatry, 0603, University of California at San Diego, La Jolla, CA 92093.

Copyright (C) 1995 Society for Neuroscience $\quad 0270-6474 / 95 / 153796-12 \$ 05.00 / 0$ poral lobe. This system includes the hippocampal region (i.e., the hippocampus proper, dentate gyrus, and subiculum) and adjacent cortical areas that are anatomically related to the hippocampal region: the entorhinal, perirhinal, and parahippocampal cortices. The amygdala is not part of this memory system (ZolaMorgan et al., 1989b, 1991; Murray, 1992).

Findings from two recent case studies (Zola-Morgan et al., 1986; Victor and Agamanolis, 1990) have provided strong support for the idea that the hippocampal region itself is critical for memory function in humans. Support for this idea has also conte from studies of monkeys with lesions that included the hippocampal region and the entorhinal and parahippocampal cortices (the $\mathrm{H}^{+}$lesion; Mishkin, 1978; Zola-Morgan and Squire, 1986; Zola-Morgan et al., 1989a). Monkeys with $\mathrm{H}^{+}$lesions exhibited significant and enduring memory impairment. However, the adjacent entorhinal and parahippocampal cortices are also important for memory function (Zola-Morgan et al., 1989c, 1993; Meunier et al., 1993; Suzuki et al., 1993). Therefore, the impairment observed in monkeys with $\mathrm{H}^{+}$lesions could result from damage to the hippocampal region alone, damage to the adjacent cortical regions, or from damage both to the hippocampal region and the adjacent cortical regions. In order to determine whether the hippocampal region alone contributes to memory, the effect of selective damage to this area needs to be systematically explored in monkeys. One problem, however, is that direct surgical removal of the hippocampal region inevitably damages adjacent cortex.

One approach to this problem has been to take advantage of the selective vulnerability of the hippocampal region to ischemia (Nadler and Evenson, 1983; Johansen et al., 1987; see Davis and Volpe, 1990, for a review). Zola-Morgan et al. (1992) found that $15 \mathrm{~min}$ of reversible ischemia in monkeys produced a significant loss of pyramidal cells in fields CA1 and CA2 of the hippocampus, together with significant and long-lasting memory impairment. Overall, the animals with ischemic lesions were not as impaired as animals with $\mathrm{H}^{+}$lesions (i.e., lesions of the hippocampal region that also include entorhinal cortex and parahippocampal cortex).

In the case of ischemic lesions, however, it is difficult to rule out entirely the idea that some damage contributing to memory impairment has occurred outside the hippocampal region and that this damage is not detected by conventional histological examination. In the present study, we used a surgical technique, which combined stereotaxic neurosurgery with magnetic resonance imaging (Alvarez-Royo et al., 1991) to make substantial bilateral lesions of the hippocampal region with little or no dannage to the adjacent cortical regions (the $\mathrm{H}$ lesion). 
Monkeys with $\mathrm{H}$ lesions were evaluated on a standard set of memory tests, including tests sensitive to human amnesia as well as tests analogous to ones that amnesic patients perform normally. To evaluate the separate contribution of the hippocampal region, the performance of the monkeys with $H$ lesions was compared with that of two other previously studicd groups: a group of monkeys with $\mathrm{H}^{+}$lesions, that is, bilateral lesions that included the hippocampal region as well as the entorhinal and parahippocampal cortices, and a group of unoperated control monkeys.

\section{Materials and Methods}

\section{Subjects}

Behavioral findings from 16 cynomolgus monkeys (Macaca fascicularis) will be presented. The animals weighed between 2.4 and $4.5 \mathrm{~kg}$ at the beginning of behavioral testing and were estimated to be 3-5 years old (Hartley et al., 1984; Szabo and Cowan, 1984).

The 16 monkeys belonged to three experimental groups. Four monkeys (all males) received bilateral lesions of the hippocampal region (i.e., the hippocampus, dentate gyrus, and subiculum; the $\mathbf{H}$ lesion). The intent was to damage the hippocampal region, while sparing the amygdala and the cortical regions adjacent to the hippocampal region (i.e., the entorhinal and parahippocampal cortices). Five monkeys (three females and two males) received lesions of the hippocampal region, the adjacent posterior entorhinal cortex and the adjacent parahippocampal cortex (the $\mathrm{H}^{+}$lesion). Behavioral data for the five monkeys in the $\mathrm{H}^{+}$ group $\left(\mathrm{H}^{+} 1-\mathrm{H}^{+} 5\right)$ have been presented previously (Zola-Morgan et al., 1993). Seven unoperated monkeys (all males) served as a normal control group (the $\mathrm{N}$ group). Behavioral data for these seven monkeys (N1N7) have also been presented previously (Zola-Morgan et al., 1992, 1993).

\section{Surgery}

$H$ group. The monkeys in the $\mathrm{H}$ group were prepared using a procedure that combined stereotaxic neurosurgery with MR techniques to improve the accuracy of lesion placement. The imaging and surgical procedures have been described in detail previously (Alvarez-Royo et al., 1991). Briefly, during a minor surgical procedure, three small glass beads filled with $0.5 \mathrm{M}$ copper sulfate $\left(\mathrm{CuSO}_{4}\right)$ were first anchored to the monkey's skull with dental acrylic. MR images of the brain were then obtained by placing the animals in a specially designed, acrylic, stereotaxic head holder that could be used safely with the MR magnet. The radio-opaque beads served as common landmarks such that lesion coordinates could be determined from the MR images and then again during neurosurgery. At the time of neurosurgery, monkeys were placed in the same stereolaxic head holder used for imaging, and craniotomies were made on each side of the brain directly over the hippocampal region. A specially designed electrode connected to a radiofrequency lesion maker was used to produce seven lesions along the rostrocaudal extent of the hippocampal region on each side of the brain. To avoid damaging the amygdala, the most anterior part of the hippocampal region immediately adjacent to the amygdala was intentionally spared (approximately $2-4 \mathrm{~mm}$ ). Furthermore, at the level of the uncus, lesions were directed only at the main hody of the hippocampal region to avoid damaging the optic tract.

$\mathrm{H}^{+}$group. The procedure for making the $\mathrm{H}^{+}$lesion has been described in detail previously (Zola-Morgan et al., 1989a). The lesion involved, bilateral aspiration of the hippocampal region (the hippocampus proper, dentate gyrus and the subicular complex) as well as most of the adjacent parahippocampal cortex and approximately the posterior laalf of the entorhinal cortex.

\section{Behavioral testing}

All groups were allowed 4-8 weeks of recovery before the start of behavioral testing. Testing was carried out in a Wisconsin General Testing Apparatus (Harlow and Bromer, 1938). During 4-6 d of pretraining, monkeys learned to obtain food by displacing objects that covered any of three food wells located on a stimulus tray in front of the testing chamber. Six tests (described in detail in Zola-Morgan et al., 1989b) were then administered in the following order: trial-unique delayed nonmatching to sample, pattern discrimination, delayed retention of object discriminations, concurrent discrimination, retest of trial-unique delayed nonmatching to sample, and motor skill learning. Three of these tasks, that is, delayed nonmatching to sample, retention of object discrimination, and concurrent discrimination are sensitive to human amnesia. The remaining tasks, that is, pattern discrimination and motor skill learning, are analogous to tasks that amnesic patients perform normally.

For trial-unique delayed nonmatching to sample, the $\mathrm{H}$ group and four of the seven animals in the $\mathrm{N}$ group were tested at delay intervals of $8 \mathrm{sec} .15 \mathrm{sec}, 60 \mathrm{sec}, 10 \mathrm{~min}$, and $40 \mathrm{~min}$. Monkeys were first trained on the delayed nonmatching to sample task using a delay interval of 8 sec until they reached a performance score of $90 \%$ correct or better in 100 trials (basic training). Animals were then tested successively at delays of $15 \mathrm{sec}$ (for 100 trials), $60 \mathrm{sec}$ (for 100 trials), $10 \mathrm{~min}$ (for 50 trials), and $40 \mathrm{~min}$ (for 50 trials). For trials with delays of $8 \mathrm{sec}, 15$ $\mathrm{sec}$, and $60 \mathrm{sec}$, animals remained in the test cage during the delay interval. For trials with delays of $10 \mathrm{~min}$ and $40 \mathrm{~min}$, animals were transferred to their home cages during the delay interval. The $\mathrm{H}^{+}$group and three animals in the $\mathrm{N}$ group were tested at delays of $8 \mathrm{sec}, 15 \mathrm{sec}$, $60 \mathrm{sec}$, and $10 \mathrm{~min}$ and were not tested at the $40 \mathrm{~min}$ delay.

\section{Histological processing}

Animals in the $\mathrm{H}$ and $\mathrm{H}^{+}$groups were administered an overdose of pentobarbital sodium (Nembutal) and perfused transcardially with a buffered, $0.9 \% \mathrm{NaCl}$ solution followed by 4 liters of $4 \%$ paraformaldehyde in $0.1 \mathrm{M}$ phosphate buffer. Brains were then blocked in situ in the coronal plane, removed from the skull, cryoprotected in $20 \%$ glycerol in $0.1 \mathrm{M}$ phosphate buffer with $2 \%$ DMSO and quick-frozen in isopentane at $-78^{\circ} \mathrm{C}$. Using a freezing microtome, $50 \mu \mathrm{m}$ coronal sections were then cut beginning at the temporal pole and continuing through a level caudal to the hippocampal region. Every fifth section was mounted and stained with thionin to assess the extent of the lesions. In addition, selected sections through the rostrocaudal extent of the temporal lobe were stained by a modification of the Heidenhain procedure for the demonstration of myelinated fibers (Hutchins and Weber, 1983).

\section{Determination of the amount of damage to the hippocampal region}

For each monkey in the $\mathrm{H}$ and $\mathrm{H}^{+}$groups, brain sections were examined at $1 \mathrm{~mm}$ intervals along the rostrocaudal extent of the hippocampus (range $=12-15$ sections). For each section, estimates of the percentage damage to the hippocampal region (including the hippocampus proper, the dentate gyrus, and the subicular complex) on the left and right sides were obtained. Specifically, a projection microscope was used to trace the intact portions of the hippocampal region in the monkeys with lesions, and a digitizing tablet was used to calculate the area of each tracing. The calculated area of intact hippocampal region on each side was then averaged to obtain an areal estimate of intact hippocampal region at that level. For each brain, the estimates for all the levels were added together and the sum was multiplied by the interslice interval ( 1 $\mathrm{mm}$ ) to obtain an estimate of the volume of spared hippocampal region. Finally, the overall estimates of spared hippocampal region for monkeys with lesions were compared to estimates of the volume of the normal hippocampal region obtained from a group of three, weight-matched, unoperated control monkeys who were a part of a separate anatomical study. In this way an estimate was obtained of the percentage damage to the hippocampal region for the monkeys in the $\mathrm{H}$ and $\mathrm{H}^{+}$groups.

\section{Determination of the amount of cortical damage}

As described in the Results section, the four monkeys in the $\mathrm{H}$ group sustained little or no damage to the cortex adjacent to the hippocampal region, that is, entorhinal, perirhinal, and parahippocampal cortex. In order to obtain a quantitative estimate of the cortical damage for each monkey in the $\mathrm{H}$ group, brain sections were examined at $1 \mathrm{~mm}$ intervals along the rostrocaudal extent of the temporal lobe (range $=16-19 \mathrm{sec}-$ tions). For each section, an estimate of the percentage damage to each of the three cortical regions adjacent to the hippocampal region, that is, the entorhinal, perirhinal, and parahippocampal cortices on the left and right sides was made by visual inspection and averaged to obtain an estimate of the overall percentage bilateral damage to each of the cortical regions at that level. The estimates of damage at all levels were then averaged to obtain an estimate of overall bilateral damage to each of the three cortical regions. The extent of damage to the entorhinal, perirhinal, and parahippocampal cortex in the monkeys with $\mathrm{H}^{+}$lesions has been described previously (Zola-Morgan et al., 1993). 
$\mathrm{H} 1$

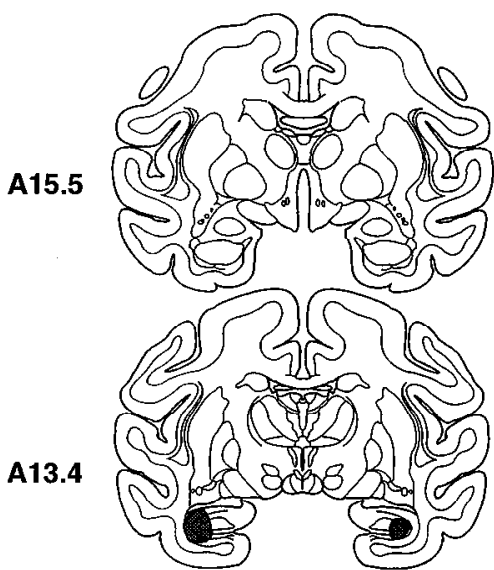

A12.1

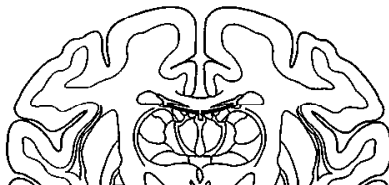

A9.6

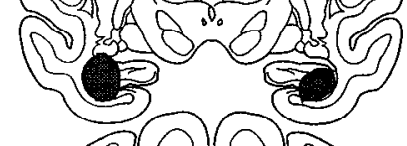

Figure 1. Representative coronal sections through the brains of the four monkeys with the $\mathrm{H}$ lesion $(H I-H 4)$, based on neurohistological analysis of brain tissue. The anteroposterior level is indicated to the left of each section, and the extent of damage is shown in gray. The most anterior portion and the most posterior portion of the hippocampal region was intentionally spared at surgery to ensure that the amygdala and visual cortex, respectively, would not be damaged.

\section{Results}

Histological findings

$H$ group. Neurohistological findings are presented here for the four monkeys in the $\mathrm{H}$ group $(\mathrm{H} \mathrm{l}-\mathrm{H} 4)$. Overall, the monkeys with $\mathrm{H}$ lesions sustained substantial bilateral damage to the hippocampal region (i.e., the hippocampus proper, the dentate gyrus and the subicular complex). The mean percentage damage for all four animals was $57 \%$. The most anterior portion and the most posterior portion of the hippocampal region were intentionally spared to prevent inadvertent damage to the amygdala and visual cortex, respectively. Accordingly, these regions sustained only mild to moderate damage. Figure 1 illustrates the extent of damage in monkeys $\mathrm{H} 1-\mathrm{H} 4$, based on neurohistological analysis of brain tissue.
$\mathrm{H} 2$
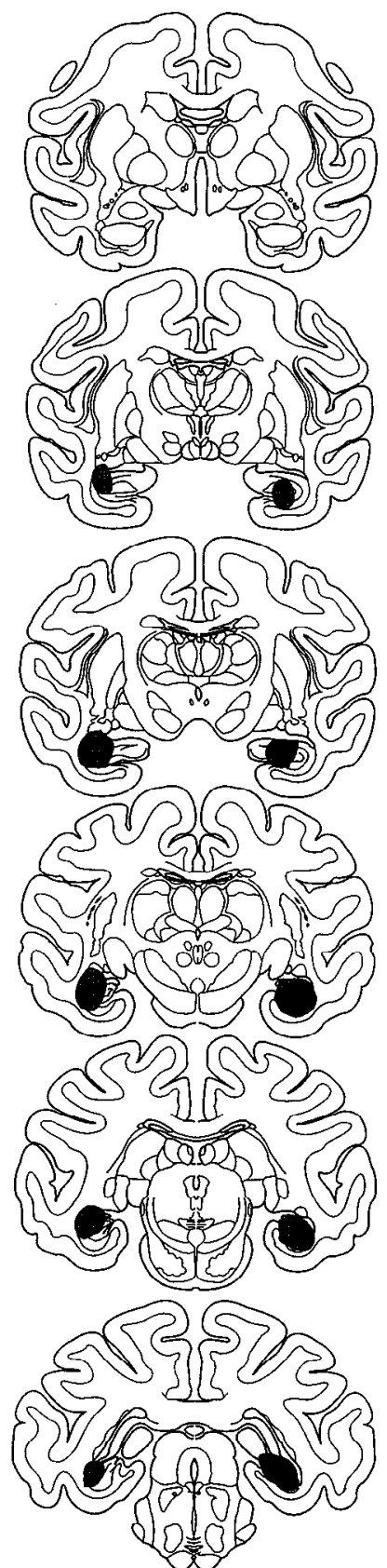

In monkey $\mathrm{H} 1$ (Fig. 2), the percentage damage to the hippocampal region including the dentate gyrus and the subiculum was $57 \%$. There was no direct damage to the amygdala, the perirhinal cortex, or the entorhinal cortex. There was a partial loss of cells in layer II of the posterior entorhinal cortex on the right side, corresponding to more extensive damage to the dentate gyrus on the right side than on the left. The posterior portion of the parahippocampal cortex sustained slight damage on the right side (overall damage to the parahippocampal cortex was less than $5 \%$ ). There was moderate and asymmetric damage to the white matter subjacent to the posterior extent of the hippocampal region. This damage involved the area of the angular bundle, which contains mainly fibers of the perforant path that originate in the entorhinal cortex and terminate in the molecular 
H3

A15.5

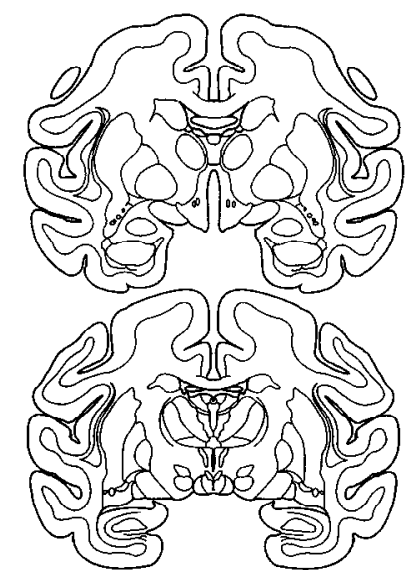

A12.1

A9.6

A6.6
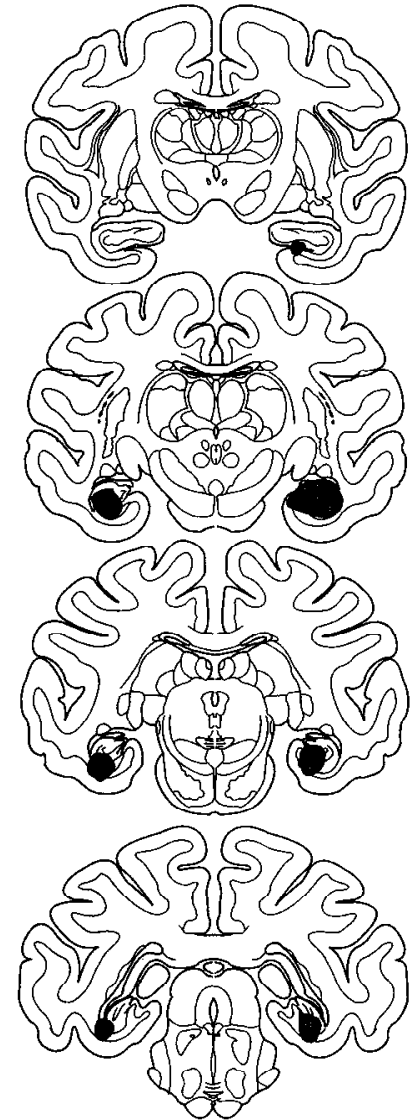

$\mathrm{H} 4$
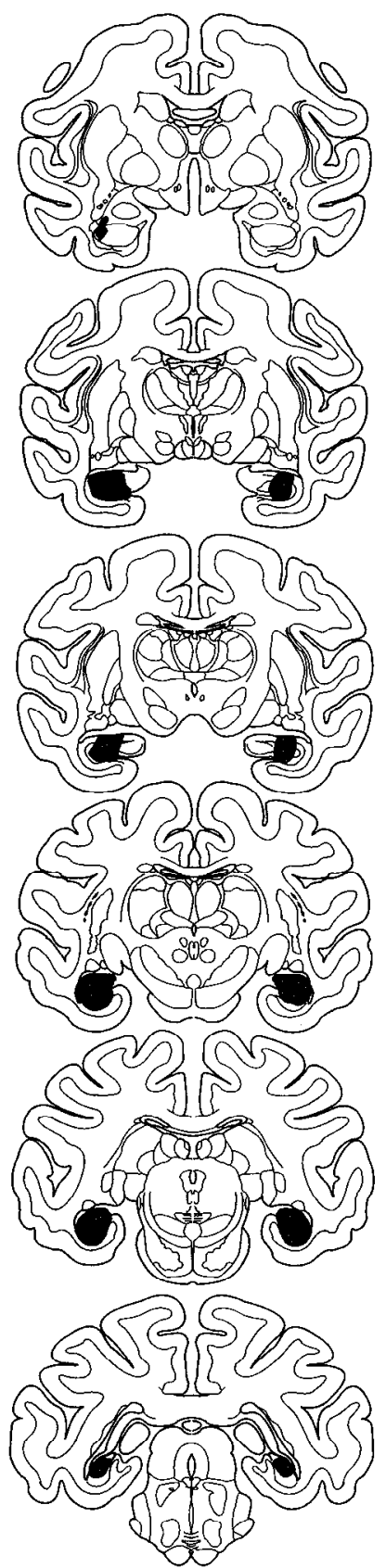

Figure I, Continued.

layer of the dentate gyrus (Insausti et al., 1987). In addition, this white matter region contains afferents and efferents of the adjacent subicular region. The most posterior portion of the tail of the caudate nucleus was damaged on the left side.

In monkey $\mathrm{H} 2$ the percentage damage to the hippocampal region was $58 \%$. There was no direct damage to the amygdala, the entorhinal, perirhinal, or the parahippocampal cortex. The dentate gyrus sustained more extensive damage on the right side than on the left and, consistent with this finding, cell loss in layer II of the posterior entorhinal cortex was substantial on the right side, but was minimal on the left side. This animal also sustained slight and asymmetric damage to the white matter subjacent to the most posterior half of the hippocampus. In addition there was severe damage to of the tail of the caudate nucleus on the left side throughout most of its rostrocaudal extent.

The lesion in monkey $\mathrm{H} 3$ began more posteriorly than in the other two monkeys. This animal sustained the least damage to the hippocampal region and the most damage to cortical and white matter areas adjacent to the hippocampal region. The percentage damage to the hippocampal region was $38 \%$. There was no damage to the amygdala, the perirhinal cortex, or the caudate nucleus. The entorhinal cortex sustained moderate damage on the right side and slight damage on the left side (overall damage to the entorhinal cortex was approximately 10\%). Except for the region of damage, layer II of entorhinal cortex appeared normal bilaterally, reflecting the substantial sparing of the dentate gyrus. 

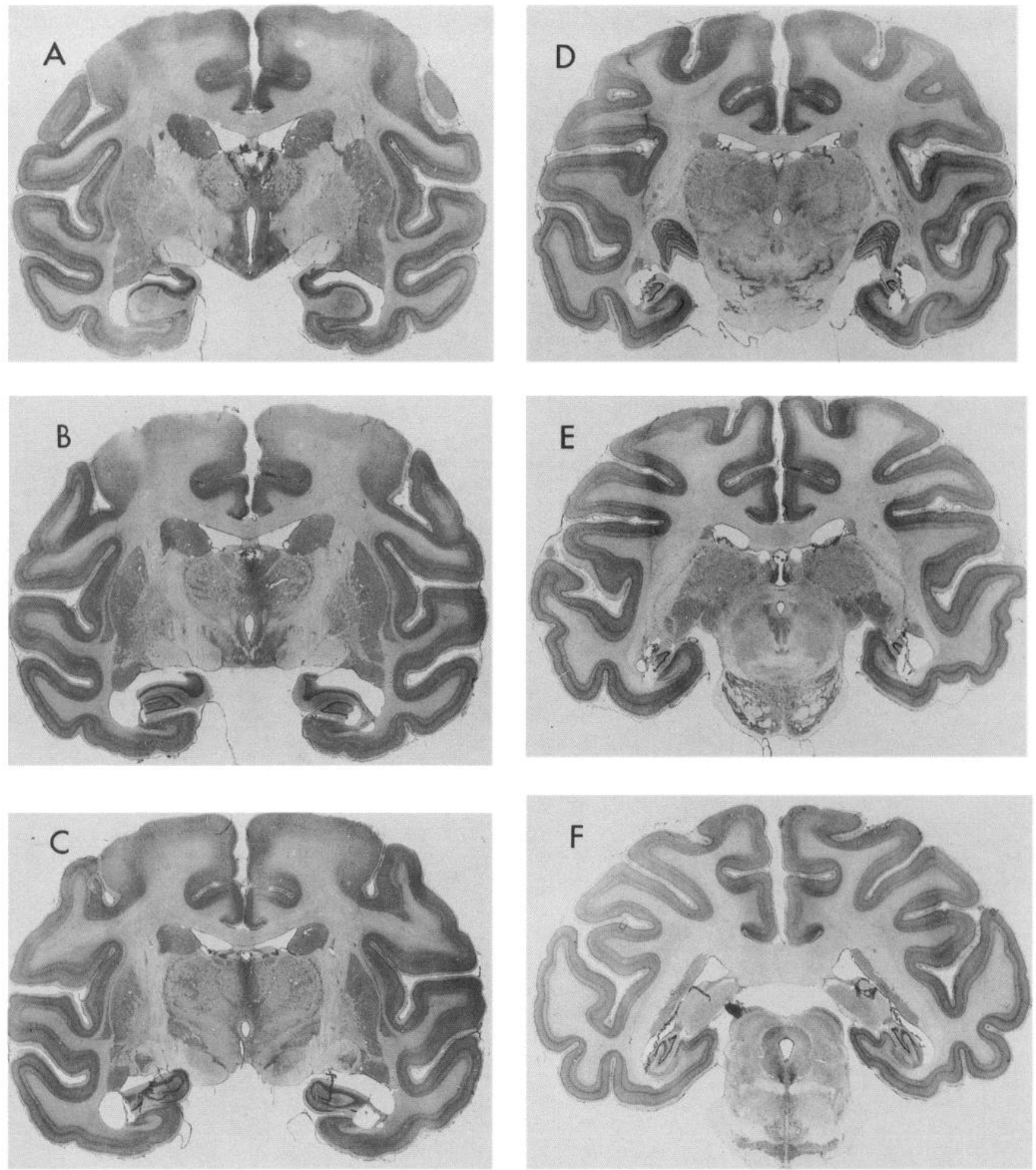

Figure 2. Photomicrographs of representative coronal sections through the temporal lobe of monkey H1. The sections are arranged from rostral $(A)$ to caudal $(F)$ and correspond approximately to anteroposterior levels A15.5 to A3.6 in Figure 1. The most anterior portion and the most posterior portion of the hippocampus were intentionally spared in order not to damage the amygdala and visual cortex, respectively. The lesion involved much of the hippocampal region bilaterally (including the dentate gyrus and the subiculum) throughout its anteroposterior extent. The posterior portion of the parahippocampal cortex sustained slight damage on the right side. The amygdala, perirhinal cortex, and entorhinal cortex were spared. Posteriorly, there was slight damage to the white matter subjacent to the posterior extent of the hippocampus. 
There was moderate damage on the left side to the white matter adjacent to area TE, and on the right side to white matter adjacent to the parahippocampal cortex. There was also moderate and asymmetric damage to the deep layers of parahippocampal cortex (overall damage to the parahippocampal cortex was approximately $15 \%$ ) and slight damage to posterior area TEO on the right side.

Monkey $\mathrm{H} 4$ sustained the most extensive and selective lesion of the hippocampal region. The percentage damage to the hippocampal region was $75 \%$. The lesion began slightly more anteriorly on the left side than on the right and there was slight damage to the ventral portion of the posterior amygdala on the left side. There was no direct damage to any of the cortical areas adjacent to the hippocampal region, that is, the entorhinal, perirhinal, or parahippocampal cortex, or to the caudate nucleus. There was substantial bilateral loss of cells in layer II of the caudal entorhinal cortex, consistent with the substantial bilateral damage to the dentate gyrus in this animal. Moderate gliosis was observed bilaterally in the angular bundle subjacent to the posterior extent of the hippocampal region, although there was no direct damage to the white matter in this region.

In summary, the four monkeys in the $H$ group sustained substantial bilateral damage to the hippocampal region, including the dentate gyrus and the subiculum (range $=38 \%$ to $75 \%$ damage). The amygdala and perirhinal cortex were spared in all four animals. The entorhinal cortex was spared except that in one animal (H3) this cortex was moderately damaged on one side and slightly damaged on the other side. In addition, the remaining three animals evidenced partial cell loss in layer II of the posterior portion of entorhinal cortex, presumably due to retrograde degeneration following damage to the dentate gyrus and or damage to the angular bundle. In animals $\mathrm{H} 1$ and $\mathrm{H} 2$, the cell loss was mainly unilateral, with minimal loss on the contralateral side. In animal $\mathrm{H} 4$ the cell loss was bilateral, corresponding to the more extensive bilateral damage to the dentate gyrus sustained by this animal. The parahippocampal cortex was slightly damaged unilaterally in one animal (H1) and moderately and asymmctrically in a sccond animal (H3). The caudate nucleus was slightly damaged unilaterally in one animal (H1) and severely damaged unilaterally in a second animal $(\mathrm{H} 2)$. In monkeys $\mathrm{H} 1-\mathrm{H} 3$ there was slight to moderate asymmetric damage to white matter subjacent to the hippocampal region, mainly in the region of the angular bundle. Moderate gliosis was observed bilaterally in the angular bundle in all four $\mathrm{H}$ monkeys. Analyses of selected fiber-stained sections also revealed decreased fiber staining in the region of the angular bundle. In addition, in the areas where tissue was spared in the hippocampal region, there was decreased staining of fibers in the perforant path and the alveus.

As described in the Discussion, none of the unintended damage (to the entorhinal cortex, the parahippocampal cortex, or the white matter subjacent to the hippocampal region) was related to performance on the memory tasks. The one animal with severe unilateral damage to the caudate nucleus performed poorly on the motor-skill task (see Results), but otherwise, there was no relationship between caudate damage and memory test performance.

$\mathrm{H}^{+}$group. Detailed descriptions of damage in the five monkeys have been published elsewhere (Zola-Morgan, et al., 1989b $\left[\mathrm{H}^{+} 1-\mathrm{H}^{+} 3\right]$; Zola-Morgan et al., $\left.1993\left[\mathrm{H}^{+} 4, \mathrm{H}^{+} 5\right]\right)$ and will only be summarized here. Animals $\mathrm{H}^{+} 1$ and $\mathrm{II}^{+} 2$ sustained nearly complete bilateral removal of the hippocampal region (percent- age damage was greater than $95 \%$ in both cases), as well as extensive bilateral damage to the entorhinal cortex. In the anterior portions of the entorhinal cortex that were spared, layer II cells were almost completely eliminated. Parahippocampal cortex in these two animals was extensively damaged bilaterally. The perirhinal cortex was damaged only slightly. In animal $\mathrm{H}^{+} 3$, the overall percentage damage to the hippocampal region was $77 \%$. Approximately the anterior third of the hippocampal region was spared bilaterally. The entorhinal cortex was intact, but there was partial loss of layer II cells. The parahippocampal cortex was damaged bilaterally, but this damage was not as extensive as in animals $\mathrm{H}^{+} \mathrm{l}$ and $\mathrm{H}^{+} 2$. The perirhinal cortex was almost entirely spared. In monkeys $\mathrm{H}^{\prime} 4$ and $\mathrm{H}^{\prime} 5$ (Zola-Morgan et al., 1993), the hippocampal region was damaged throughout its rostrocaudal extent (percentage damage was $38 \%$ and $59 \%$, respectively). Posterior entorhinal cortex was damaged bilaterally in both animals, more severely in animal $\mathrm{H}^{+} 4$. There was significant cell loss in layer II of the spared anterior portions of entorhinal cortex. Parahippocampal cortex was almost completely destroyed bilaterally (except for $1-2 \mathrm{~mm}$ posteriorly in animal $\mathrm{H}^{+} 4$ ). A small posterior region of perirhinal cortex was damaged on the left side in animal $\mathrm{H}^{+} 4$. The perirhinal cortex was almost entirely spared in animal $\mathrm{H}^{+} 5$. There was moderate damage to the left side of the posterior portion of area TE in animal $\mathrm{H}^{+} 4$, and compression of the right side of area TE in monkey $\mathrm{H}^{+} 5$. The amygdala was entirely spared in all animals in the $\mathrm{H}^{+}$group.

Quantitative analysis of the damage to the hippocampal region Overall, the extent of damage to the hippocampal region in the monkeys with $\mathrm{H}^{+}$lesions was greater than the extent of damage to the monkeys in the $\mathrm{H}$ group ( $74 \%$ vs $57 \%$, respectively; Table 1). However, because of the variability of the damage in the $\mathbf{H}^{+}$ monkeys, this difference was not statistically significant $(t[7]=$ $1.2, P>0.10$ ). This difference reflected mainly the intentional sparing of the most anterior and posterior portions of the hippocampal region in the $\mathrm{H}$ monkeys.

\section{Quantitative analysis of cortical damage}

The mean percentage damage to the entorhinal cortex for the monkeys in the $\mathrm{H}$ group was $3 \%$ (range $=0-10 \%$ ) and $30 \%$ for the $\mathrm{H}^{+}$group (range $=5-53 \%$ ). The mean percentage damage to the perirhinal cortex in the $\mathrm{H}$ group was $0 \%$, and $12 \%$ for the $\mathrm{H}^{+}$group (range $=1-22 \%$ ). The mean percentage damage to the parahippocampal cortex for the monkeys in the $\mathrm{H}$ group was $5 \%$ (range $-0-15 \%$ ) and $94 \%$ for the $\mathrm{H}^{+}$group (range = $87-99 \%)$.

\section{Behavioral findings}

Table 1 shows the performance scores for monkeys in the $\mathrm{N}, \mathrm{H}$, and $\mathrm{H}^{+}$groups on three memory tasks shown previously to be sensitive to medial temporal lobe damage: delayed nonmatching to sample (the scores are the average scores across the two separate administrations of the test), delayed retention of object discriminations, and concurrent discrimination.

Delayed nonmatching to sample. This task was administered to all the groups on two different occasions. The first administration occurred 4-8 weeks after surgery, immediately after the completion of pretraining, and the second administration occurred after completion of testing on three other tasks (pattern discrimination, delayed retention of object discriminations, and eight-pair concurrent discrimination learning). The interval between the first and second tests was 6-9 months for the $\mathrm{N}$ group, 


\begin{tabular}{|c|c|c|c|c|c|c|c|c|c|c|c|}
\hline \multirow[b]{4}{*}{ Group } & \multirow{4}{*}{$\begin{array}{l}\% \\
\text { Danlage } \\
\text { to } \\
\text { hippo- } \\
\text { campal } \\
\text { region }\end{array}$} & \multicolumn{8}{|c|}{ Delayed nonmatching to sample } & \multirow{4}{*}{$\begin{array}{l}\text { Object } \\
\text { reten- } \\
\text { tion }\end{array}$} & \multirow{4}{*}{$\begin{array}{l}\text { Con- } \\
\text { curren } \\
\text { discri- } \\
\text { mina- } \\
\text { tion } \\
\end{array}$} \\
\hline & & \multirow{2}{*}{\multicolumn{2}{|c|}{$\begin{array}{l}\text { Trials to } \\
\text { critcrion }\end{array}$}} & \multicolumn{6}{|c|}{ Delays } & & \\
\hline & & & & 8 & 15 & 60 & 10 & 40 & Mean & & \\
\hline & & 1 & 2 & $\mathrm{sec}$ & sec & $\sec$ & $\min$ & $\min$ & of 3 & & \\
\hline \multicolumn{12}{|l|}{ Normal } \\
\hline 1 & - & 180 & 0 & 92 & 93 & 89 & 73 & 75 & 85 & 88 & 240 \\
\hline 2 & - & 440 & 0 & 92 & 94 & 94 & 70 & 69 & 86 & 88 & 720 \\
\hline 3 & - & 220 & 0 & 91 & 93 & 88 & 79 & 72 & 87 & 85 & 640 \\
\hline 4 & - & 120 & 20 & 92 & 97 & 91 & 83 & 76 & 90 & 86 & 240 \\
\hline 5 & - & 180 & 0 & 91 & 94 & 85 & 75 & - & 85 & 85 & 360 \\
\hline 6 & - & 160 & 0 & 92 & 93 & 95 & 83 & - & 90 & 86 & 480 \\
\hline 7 & - & 80 & 80 & 91 & 84 & 88 & 86 & - & 86 & 87 & 600 \\
\hline Mean & - & 197 & 14 & 92 & 93 & 90 & 78 & 73 & 87 & 86 & 469 \\
\hline \multicolumn{12}{|l|}{ II } \\
\hline 1 & 57 & 520 & 0 & 93 & 95 & 90 & 71 & 62 & 85 & 82 & 320 \\
\hline 2 & 58 & 73 & 100 & 90 & 95 & 90 & 63 & 61 & 83 & 87 & 400 \\
\hline 3 & 38 & 310 & 0 & 92 & 96 & 92 & 76 & 68 & 88 & 87 & 360 \\
\hline 4 & 75 & 255 & 0 & 92 & 95 & 88 & 64 & 57 & 82 & 82 & 320 \\
\hline Mean & 57 & 290 & 25 & 92 & 95 & 90 & 69 & 62 & 85 & 85 & 350 \\
\hline \multicolumn{12}{|l|}{$\mathrm{H}^{+}$} \\
\hline 1 & 96 & 260 & 20 & 91 & 89 & 73 & 65 & - & 76 & 75 & 760 \\
\hline 2 & 100 & 520 & 0 & 91 & 92 & 85 & 62 & - & 80 & 72 & 720 \\
\hline 3 & 77 & 840 & 0 & 91 & 93 & 92 & 64 & - & 83 & 80 & 880 \\
\hline 4 & 38 & 150 & 100 & 91 & 85 & 85 & 68 & - & 79 & 63 & 1510 \\
\hline 5 & 59 & 80 & 60 & 91 & 90 & 82 & 64 & - & 79 & 76 & 950 \\
\hline Mean & 74 & 370 & 36 & 91 & 90 & 83 & 65 & - & 79 & 73 & 964 \\
\hline
\end{tabular}

For the delayed nonmatching to sample task, the scores for trials to criterion are the number of trials required to reach the learning criterion the first (left column) and second (right column) time that the task was administered. Delay scores are the percentage correct scores for each delay averaged across the two times the task was administered. - indicates that an animal was not tested at this delay. The "Mean of 3" scores are the percentage correct scores averaged across the three delays $(15 \mathrm{sec}, 60 \mathrm{sec}$, and $10 \mathrm{~min}$ ). The scores for the object retention task are the percentage correct scores for four discriminations averaged across 3 test days. The scores for the concurrent discrimination are the number of trials required to reach the learning criterion.

6-9 months for the $\mathrm{H}$ group, and 18-41 months for the $\mathrm{H}^{+}$ group.

Basic task ( $8 \mathrm{sec}$ delay). Figure $3 A$ shows the mean number of trials required to learn the basic $(8 \mathrm{sec})$ task on the two oc- casions it was given. On the first administration of the task, the $\mathrm{H}$ and $\mathrm{H}^{+}$groups both required numerically more trials to reach criterion than the normal group (means of 290 trials, 370 trials, and 197 trials, respectively), but none of the differences between

Figure 3. A, Initial learning of the delayed nonmatching to sample task with a delay of $8 \mathrm{sec}$ for normal monkeys $(N)$, monkeys with lesions of the hippocampal region $(H)$, and monkeys with lesions of the hippocampal region, the posterior entorhinal cortex, and the parahippocampal cortex $\left(\mathrm{H}^{+}\right)$. Monkeys were tested on two different occasions (first test, open bars; second test, solid bars). Individual scores are presented in Table 1. B, Performance across delays on the delayed nonmatching to sample task for groups $N, H$, and $H^{+}$. For each monkey, performance scores for the two administrations of the test were averaged together. All animals were tested with delays of $15 \mathrm{sec}$, $60 \mathrm{sec}$, and $10 \mathrm{~min}$. Four normal animals (N4-N7) and the $\mathrm{H}$ group were also tested with a delay interval of 40 min.

A.

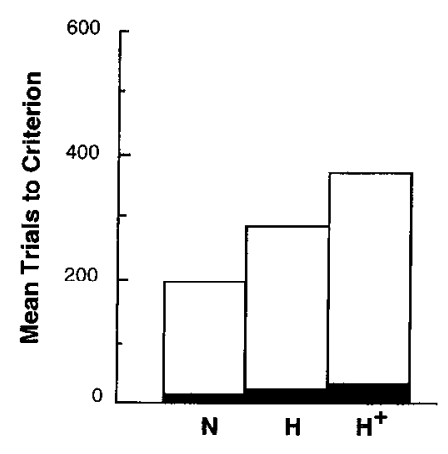

B.

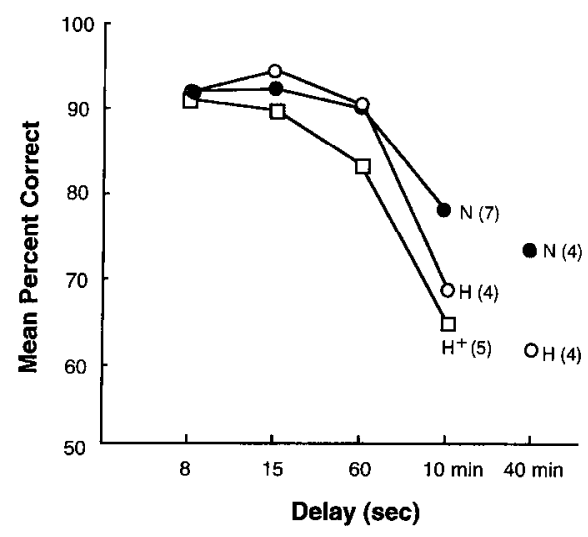




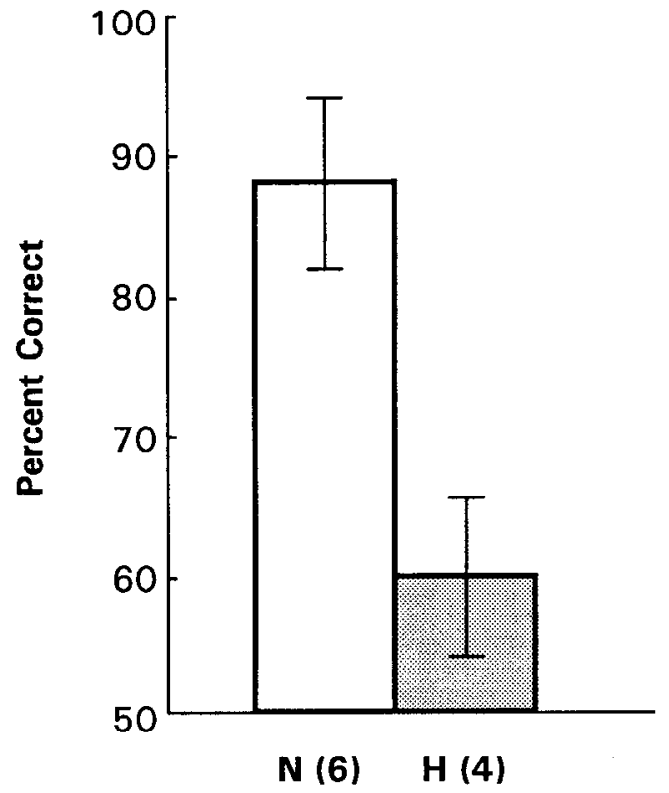

Figure 4. Performance on the first 10 trials of the first day of training on the delayed nonmatching to sample task with a delay of $8 \mathrm{sec}$ for normal monkeys $(N)$ and monkeys with lesions of the hippocampal region $(H)$. See text for description of monkeys that comprise the $\mathrm{N}$ group. Error bars represent SEs.

groups was significant (all $t \mathrm{~s}<1.4$; all $P_{\mathrm{s}}>1.0$ ). On the second administration of the task, the $\mathrm{H}$ and $\mathrm{H}^{+}$groups again required numerically more trials than normal monkeys to reach criterion (Table 1 ), and again none of the betweengroup comparisons was significant (all $t$ values $<1.1$; all $P$ values $>0.10$ ).

Basic task: performance on the first 10 trials of training. The delayed nonmatching task takes advantage of the normal tendency of monkeys to prefer the novel object in a two-choice test. Tasks that depend on spontaneous tendencies have proven especially sensitive to hippocampal lesions (for example, Roberts et al., 1962; Wood and Phillips, 1991; Bachevalier et al., 1993). Accordingly, for the four $\mathrm{H}$ monkeys and for six of the normal monkeys from the present study we examined the first 10 trials of the first day of training on the delayed nonmatching to sample task (the data for monkey N7 could not be included in the analysis because this monkey exhibited motivational problems and completed only five trials on the first day of testing). During these first few trials of training, performance primarily reflects the spontaneous tendency to select the novel object rather than knowledge of the nonmatching rule. Monkeys with $\mathrm{H}$ lesions were impaired during the first 10 trials of the first day of training (Fig. 4). Normal monkeys scored $88 \%$ correct, and the monkeys with $\mathrm{H}$ lesions scored $60 \%$ correct $[t(8)=3.2 ; P$ $<0.05]$.

Delays ( $15 \mathrm{sec}, 60 \mathrm{sec}, 10 \mathrm{~min}, 40 \mathrm{~min}$ ). For each group, the scores obtained on the first and second tests were not significantly different (N group: $94 \%, 89 \%, 79 \%$, and $65 \%$ on the first test; $91 \%, 90 \%, 77 \%$, and $80 \%$ on the second test (only monkeys N1-N4 were tested at the 40 min delay); $\mathrm{H}$ group: $95 \%, 90 \%$, $68 \%$, and $61 \%$ on the first test; $95 \%, 90 \%, 70 \%$, and $63 \%$ on the second test; $\mathrm{H}^{+}$group (the $\mathrm{H}^{+}$group was not tested at the 40 min delay): $89 \%, 85 \%$, and $66 \%$ on the first test; $91 \%, 82 \%$, and $63 \%$ on the second test; two way ANOVA for each group (test $X$ delay): $\mathrm{H}$ and $\mathrm{H}^{+}$groups: test, $F$ values $<0.24, P$ values
$>0.10$; delay, $F$ values $>41, P<0.001$; test $\times$ delay, $F$ values $<0.80, P$ values $>0.10 ; \mathrm{N}$ group: test, $F=3.12, P>0.10$; delay, $F=28.1, P<0.001$; test $\times$ delay, $F=3.46, P=0.073$; the marginally significant interaction for the $N$ group was due to the fact that this group exhibited improved performance at the 40 min delay interval on the second test). Because the performance on delays was similar on the first and second administrations of the test, the performance scores for the first and second tests were averaged together for further comparisons between groups.

Figure $3 B$ shows performance on the delays averaged across the two test administrations. A two-way analysis of variance (groups $\times$ delay) was first carried out to compare the $\mathrm{H}$ and $\mathrm{N}$ groups at the delays presented to all the animals (i.e., $15 \mathrm{sec}, 60$ $\mathrm{sec}$, and $10 \mathrm{~min})$. The important finding was a significant group $X$ delay interaction $(F[2,18]=5.9, P<0.05)$, due to the poor performance of the $\mathbf{H}$ group at the longest delay. There was also a significant effect of delay $(F[2,18]=62.9, P<0.001)$, but no effect of group because the $\mathrm{H}$ animals performed well through the $60 \mathrm{sec}$ delay $(F[1,6]=2.4, P>0.10)$. Analysis of simple main effects indicated that the two groups differed at the 10 min delay $(F[1,24]=13.4, P<0.01)$. A post hoc test $(\mathrm{Tu}-$ key's HSD) also showed a significant difference at the $10 \mathrm{~min}$ delay $(P<0.05)$. Finally, a separate analysis for the $40 \mathrm{~min}$ delay revealed that the animals with $\mathrm{H}$ lesions performed worse than normal animals $(t[6]=3.9, P<0.01)$. Thus, the $\mathrm{H}$ animals were impaired at the $10 \mathrm{~min}$ and $40 \mathrm{~min}$ delays.

Next, the $\mathrm{H}$ and $\mathrm{H}^{+}$groups were compared (two-way analysis of variance, two groups, three delays; $15 \mathrm{sec}, 60 \mathrm{sec}$, and 10 $\min )$. There was a significant effect of group $(F[1,7]=9.1, P$ $<0.05)$, indicating that the $\mathrm{H}^{+}$group performed worse overall, a significant effect of delay $(F[2,14]=96.6, P<0.001)$, and no group $X$ delay interaction $(F[2,14]=3.9, P>0.10)$. Analyses of simple main effects found a marginally significant difference at the $15 \mathrm{sec}$ delay $(F[1,20]=3.8, P<0.07)$, a significant difference at the $60 \mathrm{sec}$ delay $(F[1,20]=5.5, P<0.05)$, and no difference at the 10 min delay $(F[1,20]=1.9, P>0.10)$.

In summary, the $\mathrm{H}$ lesion produced significant impairment on the delayed nonmatching to sample task, which was evident at both the $10 \mathrm{~min}$ and $40 \mathrm{~min}$ delays. As measured by performance on the delay intervals tested in common in the $\mathrm{H}$ and $\mathrm{H}^{+}$ groups (15 sec, $60 \mathrm{sec}$, and $10 \mathrm{~min}$ ), the overall level of impairment in the $\mathrm{H}$ group was not as severe as the impairment associated with the $\mathrm{H}^{+}$lesion. Finally, the effects of the $\mathrm{H}$ lesion were enduring. Specifically, the performance of the $\mathrm{H}$ group at the $10 \mathrm{~min}$ and $40 \mathrm{~min}$ delays of the delayed nonmatching to sample task was no better when the task was administered the second time than when it was first administered 6-9 months earlier $(10$ min delay: second test $=70 \%$, first test $=68 \% ; 40$ min delay: second test $=63 \%$, first test $=61 \%, t$ values $<0.06$, $P$ values $>0.10$ ). Finally, a separate analysis of the retest scores for the $\mathrm{H}$ and $\mathrm{N}$ groups indicated that the $\mathrm{H}$ monkeys were impaired at the 40 min delay $(\mathrm{N}$ group $=80 \%$ correct, $\mathrm{H}$ group $=63 \%, P<0.01$ ). The $\mathrm{H}$ group was also numerically worse than the $\mathrm{N}$ group at the 10 min delay $(\mathrm{N}$ group $=77 \%$ correct, $\mathrm{H}$ group $=70 \%$ correct $)$, but this difference did not reach statistical significance $(P>0.10)$.

Pattern discrimination. The number of trials required to learn the two pattern discrimination problems were averaged for each monkey (Fig. 5). Monkeys $\mathrm{N} 1$ and $\mathrm{H}^{+} 4$ performed continually at chance level on both problems, and testing on each problem was discontinued after 1000 trials. These animals were assigned 


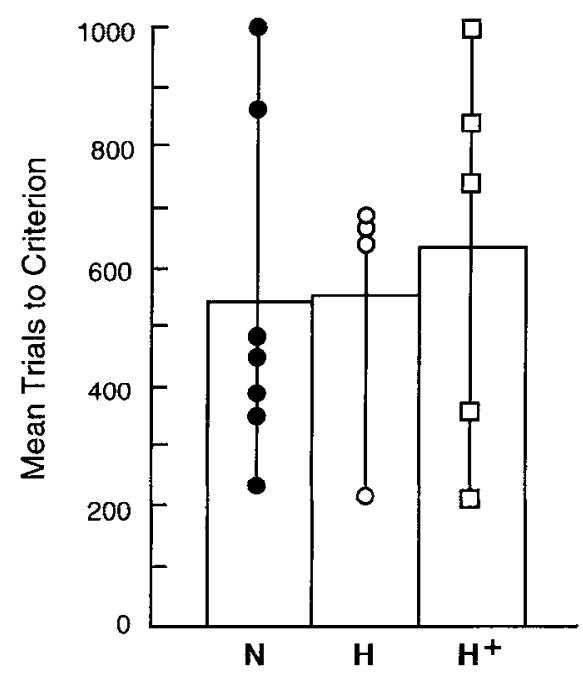

Figure 5. Mean scores on two pattern discrimination tasks for normal monkeys $(N)$, monkeys with lesions of the hippocampal region $(I I)$, and monkeys with lesions of the hippocampal region, posterior entorhinal cortex and parahippocampal cortex $\left(\mathrm{H}^{+}\right)$. Symbols show scores for individual monkeys.

a mean score of 1000 trials. Monkeys $\mathrm{N} 3, \mathrm{H}^{+} 3$, and $\mathrm{H}^{+} 5$ performed continually at chance level on one of the problems through 1000 test trials, and these animals were assigned a score of 1000 trials for that problem. (Monkeys N1 and N3 were referred to as N4 and N6 in Zola-Morgan et al., 1989c). There were no differences between any of the groups in terms of the number of trials required to learn the pattern discrimination problems (all $t$ values $<0.6$, all $P$ values $>0.10$ ).

Delayed retention of object discriminations. The data for all four discriminations were averaged together for each animal. Overall, performance averaged across all $3 \mathrm{~d}$ of testing (Fig. 6, Table 1), showed that the $\mathrm{H}$ group was not impaired $(\mathrm{N}=86 \%$, $\mathrm{H}=85 \%, t[9]=1.64, P>0.10)$. The $\mathrm{H}^{+}$group performed significantly worse than both the $\mathrm{N}$ and $\mathrm{H}$ groups $\left(\mathrm{H}^{+}=73 \%\right.$; both $t$ values $>3.2$, both $P$ values $<0.05$ ).

Another way of describing these data is to note the number of trials needed to reach a criterion of 9 out of 10 correct trials. Normal monkeys required a median of 11 trials to learn the four tasks (medians are used here to permit direct comparisons with the findings reported in Zola-Morgan and Squire, 1985, and Zola-Morgan et al., 1989a,b, 1992, 1993), H monkeys required 13 trials, and $\mathrm{H}^{+}$monkeys required 20 trials. By this measure, the $\mathrm{H}^{+}$group performed more poorly than the $\mathrm{N}$ group $(t[10]=$ $3.1, P<0.01)$, but the $\mathrm{H}$ group did not $(P>0.10)$. Although the score for the $\mathrm{H}^{+}$group was lower than the score for the $\mathrm{H}$ group, the difference did not reach statistical significance $(P>$ $0.10)$.

Concurrent discrimination. Figure 7 and Table 1 show that the $\mathrm{H}$ group (mean trials to criterion, 350) performed as well as the $\mathrm{N}$ group (mean trials to critcrion, 469; $t[9]=1.60, P>$ 0.10 ). The $\mathrm{H}^{+}$group (mean trials to criterion, 964) performed more poorly than both the $\mathrm{N}$ group and the $\mathrm{H}$ group (both $t$ values $>3.3$, both $P$ values $<0.01$ ).

Lifesaver motor skill task. Only three of the four monkeys in the $\mathrm{H}$ group were tested. Of the three $\mathrm{H}$ monkeys, two animals $(\mathrm{H} 1$ and $\mathrm{H} 4)$ acquired the task at a normal rate, improving from an average of $24.2 \mathrm{sec}$ to retrieve the lifesaver in the first session to a mean of $5.6 \mathrm{sec}$ in the last session. The third animal (H2,

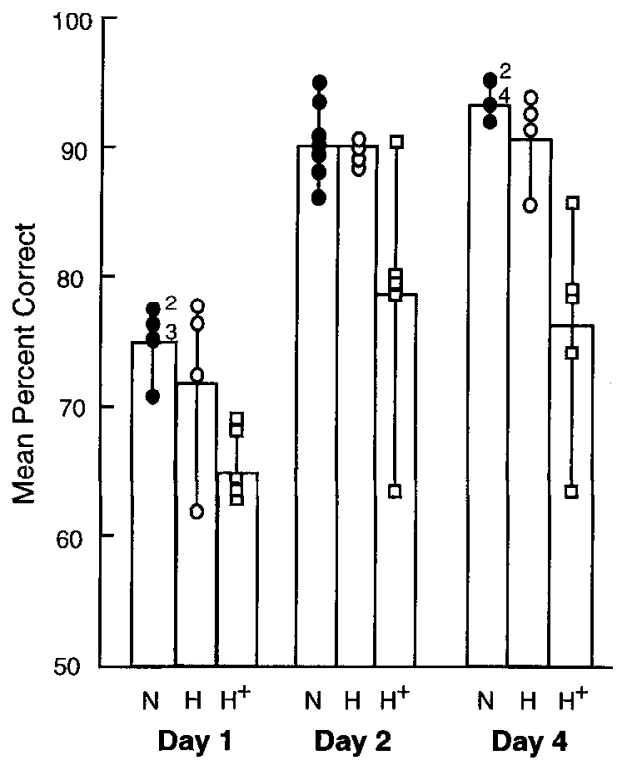

Figure 6. Average daily performance on four object discrimination tasks for normal monkeys $(N)$, monkeys with lesions of the hippocampal region $(H)$, and monkeys with lesions of the hippocampal region, posterior entorhinal cortex and parahippocampal cortex $\left(\mathrm{H}^{+}\right)$. Symbols show scores for individual monkeys. Numbers beside symbol indicate the number of monkeys that obtained the same score.

with severe damage to the tail of the caudate nucleus) learned slowly during the $d$ of training that are ordinarily given for this task, but then autained normal levels of performance during two additional training days that immediately followed the first 8 training days. The $\mathrm{H}^{+}$group learned at a normal rate. One month after the final session of initial learning, all groups were retested for two consecutive daily sessions. All groups showed evidence of retention (mean score for both test days: $\mathrm{N}=5.2$ sec; $\left.\mathrm{H}=9.9 \mathrm{sec} ; \mathrm{H}^{+}=4.9 \mathrm{sec}\right)$. Nevertheless, the $H$ group did

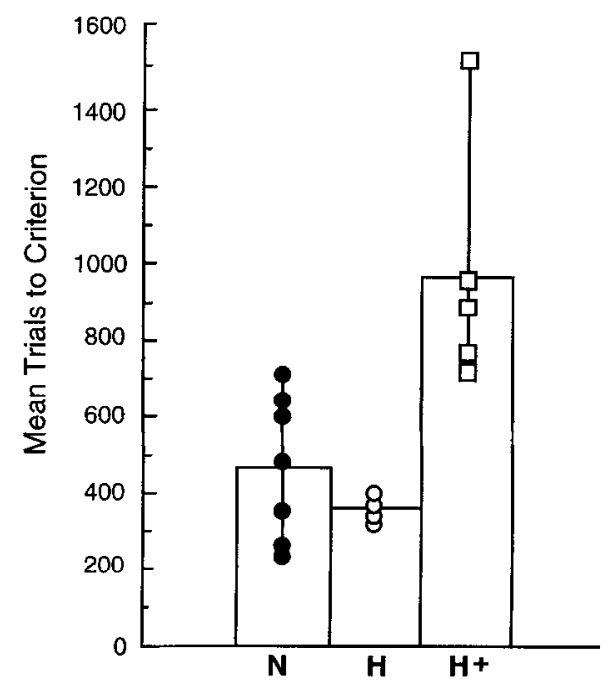

Figure 7. Number of trials needed to reach criterion level performance on the eight-pair concurrent discrimination task by normal monkeys $(N)$, monkeys with lesions of the hippocampal region $(H)$, and monkeys with lesions of the hippocampal region, posterior entorhinal cortex and parahippocampal cortex $\left(\mathrm{H}^{+}\right)$. Symbols show scores for individual monkeys. 
perform worse than the $\mathrm{N}$ group $(t[8]=2.7, P<0.05)$. The difference between the $\mathrm{H}$ and $\mathrm{H}^{+}$groups was not significant $(t[5]$ $=0.52, P>0.10$ ).

\section{Discussion}

The main finding was that lesions limited to the hippocampal region (i.e., the dentate gyrus, hippocampus proper, and subiculum) were sufficient to produce long-lasting memory impairment. As discussed below, the impairment of the $\mathrm{H}$ monkeys was less severe than that observed in monkeys with lesions of the hippocampal region that also included the entorhinal and parahippocampal cortices (the $\mathrm{H}^{+}$lesion). Specifically, on the delayed nonmatching to sample task (scores for the first and second test averaged together), the $\mathrm{H}$ monkeys were significantly impaired at each of the two longest delay intervals (the $10 \mathrm{~min}$ and 40 min delays). Also, they showed no improvement in their scores when they were retested at the same delay intervals 6-9 months after the first test.

The $\mathrm{H}$ monkeys were unimpaired on delayed retention of object discriminations and the eight-pair concurrent discrimination task, (Table 1, Figs. 6, 7). Finally, the $\mathrm{H}$ monkeys learned the two pattern discrimination problems normally, and with the exception of monkey $\mathrm{H} 2$ (discussed below) they were normal at learning the Lifesaver motor skill task.

The finding that damage limited to the hippocampal region in monkeys produced detectable memory impairment is consistent with an earlier report of enduring memory impairment in monkeys after ischemic damage limited to the hippocampal region (Zola-Morgan et al., 1992; see below) and with two preliminary studies that reported impaired memory in monkeys with lesions of the hippocampal region made with ibotenic acid (BeasonHeld et al., 1993; Murray and Gaffan, 1993). Another preliminary study reported finding no impairment on the delayed nonmatching to sample task following ibotenate lesions that included the hippocampal region (O'Boyle et al., 1993). However, in this study the delay intervals were relatively short (i.e., $2 \mathrm{~min}$ and less on the standard part of the task, and up to $3.5 \mathrm{~min}$ on another part of the task). Moreover, the monkeys were trained on the task preoperatively (a condition known to facilitate postoperative performance scores; Zola-Morgan and Squire, 1986; Ringo, 1988). Accordingly, it seems likely that the study by O'Boyle et al. (1993) did not detect an impairment because the task, as it was administered, was insufficiently sensitive.

In the present study, the memory impairment following the $\mathrm{H}$ lesions was apparent only on the delayed nonmatching to sample task, and then only at $10 \mathrm{~min}$ and $40 \mathrm{~min}$ delays, and not at the shorter $15 \mathrm{sec}$ and $60 \mathrm{sec}$ delays. From these findings, one might suppose that the hippocampal region generally makes no contribution to memory functions in the first $10 \mathrm{~min}$ after a learning trial. However, there are other possibilities that also account for the pattern of findings observed here, including the possibility that the delayed nonmatching task is simply not sensitive enough at the shorter delays to detect impaired performance reliably after damage to the hippocampal region.

Tasks that depend on spontaneous novelty preference appear to be particularly sensitive to hippocampal damage (Roberts et al., 1962; Wood and Phillips, 1991; Bachevalier et al., 1993). For example, monkeys with lesions of the fornix were shown to perform normally at a short delay $(10 \mathrm{sec})$ on the standard delayed nonmatching to sample task (Gaffan, 1974), but in a second study fornix lesions impaired performancc on spontancous nonmatching to sample at the same $10 \mathrm{sec}$ delay (Gaffan et al.,
1984). Accordingly, we examined the performance of the monkeys in the $\mathrm{H}$ group and the performance of the normal monkeys at the very early stages of training on the delayed nonmatching to sample task when the animals presumably have not yet learned the rule that affects the availability of reward. Above chance performance at this early stage of testing likely reflects spontaneous preference for the novel objects presented on the choice phase of each trial. The monkeys with $\mathrm{H}$ lesions were impaired during the first 10 trials of the first day of training on the basic task $(8 \mathrm{sec})$ portion of the delayed nonmatching to sample task $(P<0.05$; Fig. 4). Additional analyses revealed that the monkeys with $\mathrm{H}$ lesions were impaired on all but three of the first 10 trials (impaired on trials 2, 3, 6, 7-10: $P$ values $<0.05$; trials $1,4,5: P$ values $>0.06$ )

It is important to note that, in humans, tasks that measure spontaneous nonmatching have not revealed an impairment when the choice phase is scheduled immediately after the exposure phase or learning phase (i.e., 0 sec delay; McKee and Squire, 1993). Thus, the impairment likely reflects a memory deficit, not some difficulty in reacting to novelty per se.

We also considered the possibility that the impairment following $\mathrm{H}$ lesions occurred only at the $10 \mathrm{~min}$ and $40 \mathrm{~min}$ delays, and not at the shorter delays, because monkeys were returned to their home cages during the long delay intervals. That is, what is the effect the long delay alone, the distraction associated with returning to the home cage, and the combination of both conditions? Two findings are germane to this issue. First, as discussed above, $\mathrm{H}$ lesions can impair memory even at short ( 8 $\mathrm{sec})$ delays without distraction. Second, it is not clear that returning to the home cage has a disruptive effect on performance. For 50 trials, using a $10 \mathrm{~min}$ delay, three normal monkeys averaged $80 \%$ correct on the 25 trials when they were returned to their home cage, and $77 \%$ correct on the 25 trials when they remained in the testing cage during the 10 min delay $(P>0.10$; unpublished observations).

The finding that bilateral damage limited to the hippocampal region produces significant and long-lasting memory impairment in monkeys is consistent with findings from studies of human amnesia (Zola-Morgan et al., 1986; Victor and Agamanolis, 1990). Finding of impaired memory following damage limited to the hippocampal region has also been reported in rats (for reviews, see Jarrard, 1993; Jaffard and Meunier, 1993). Accordingly, the findings in rats, monkeys, and humans are in agreement that damage limited to the hippocampal region can produce significant and, in some cases, long-lasting memory impairment.

The $H$ group versus the $H^{+}$group. The memory impairment of the $\mathbf{H}$ monkeys was less severe overall than the impairment associated with surgical lesions of the hippocampal region that included the entorhinal cortex and the parahippocampal cortex (the $\mathrm{H}^{+}$group). When each group's scores were averaged across the three delays of the nonmatching task ( $15 \mathrm{sec}, 60 \mathrm{sec}$, and 10 min), the $\mathrm{H}^{+}$group (79\% correct) performed significantly worse than the $\mathrm{H}$ group $(85 \%$ correct; $t[7]=2.8, P<0.05)$. In addition, the $\mathrm{H}^{+}$group performed significantly worse than the $\mathrm{H}$ group on the delayed retention of object discriminations and on the concurrent discrimination task (Table 1).

The overall extent of bilateral damage to the hippocampal region was numerically less in the $H$ group $(57 \%)$ than in the $\mathrm{H}^{+}$group $(74 \%)$ (see Results section), although this overall difference was not statistically significant. A detailed analysis of the data argues against the idea that the overall difference in extent of damage to the hippocampal region between the $\mathrm{H}$ and 
$\mathrm{H}^{+}$groups could have contributed to the observed differences in performance. Monkey $\mathrm{H}^{+} 4$ had approximately $38 \%$ bilateral damage to the hippocampal region, an amount of damage less than three of the four monkeys in the $\mathbf{H}$ group (Table 1). Yet, monkey $\mathrm{H}^{+} 4$ performed consistently worse than all of the animals in the $\mathrm{H}$ group on the amnesia-sensitive tasks (Table 1).

Another way of making this same point is to compare the performance scores of monkey $\mathrm{H}^{+} 4$ and monkey $\mathrm{H} 3$, whose percentage damage to the hippocampal region was identical (38\%). Monkey $\mathrm{H}^{+} 4$ performed more poorly than monkey $\mathrm{H} 3$ on delayed nonmatching to sample (score averaged across the three delays: $\left.\mathrm{H}^{+} 4=79 \%, \mathrm{H} 3=88 \%\right)$, delayed retention of object discriminations (score averaged across three test days: $\mathrm{H}^{+} 4=63 \%, \mathrm{H} 3=87 \%$ ), and concurrent discrimination (trials to criterion: $\mathrm{H}^{+} 4=1510, \mathrm{H} 3=360$ )

Taken together, these data suggest that the more severe memory impairment in the $\mathrm{H}^{+}$group is due to the extensive damage to the entorhinal and parahippocampal cortices that occurred in the $\mathrm{H}^{+}$group but not in the $\mathrm{H}$ group. This idea is consistent with several recent studies in monkeys and rats that have pointed to the importance of these cortical regions to memory (Mumby and Pinel, 1994; Otto and Eichenbaum, 1992; Bunsey and Eichenbaum, 1993; Meunier et al., 1993; Suzuki et al., 1993; ZolaMorgan et al., 1993, 1994; for reviews, see Eichenbaum et al., 1992; Jaffard and Meunier, 1993; Zola-Morgan and Squire, 1993).

Because of the importance for memory of the cortical regions adjacent to the hippocampal region, it is important to consider for the $\mathrm{H}$ group the possible significance of inadvertent damage to this adjacent cortex as well as inadvertent damage to the white matter adjacent to the hippocampal region. Damage to the entorhinal cortex and parahippocampal cortex was only moderate and asymmetrical. Moreover, there was no evidence of a consistent relationship between the impairment observed in the delayed nonmatching to sample task and damage to the cortex. For example, monkey H3 sustained the greatest amount of cortical damage but the least amount of damage to the hippocampal region itself. This monkey obtained less impaired scores on the delayed nonmatching to sample task at delays of $10 \mathrm{~min}$ and 40 min than the other three monkeys in the $\mathrm{H}$ group who had no damage to entorhinal cortex (Table 1). Moreover, monkey $\mathrm{H} 4$, who sustained no direct cortical damage, obtained the most impaired scores on the delayed nonmatching to sample task ( 40 min delay and Mean3, Table 1).

With respect to white matter damage in the $\mathrm{H}$ monkeys, which like the cortical damage was also moderate and asymmetrical, one possible concern is that the memory impairment exhibited by the monkeys in the $H$ group might depend on significant cell loss in the entorhinal cortex, a region where lesions have been reported to produce memory impairment in monkeys (Leonard et al., in press) and in rats (see, for example, Otto and Eichenbaum, 1992; for a review, see Jarrard, 1993). Cell loss in the entorhinal cortex could have resulted from retrograde degeneration in the perforant path, which travels in the white matter region that was damaged in the $\mathrm{H}$ monkeys (Fig. 1). Three points address this issue. First, detailed examination of entorhinal cortex revealed only partial and mainly unilateral cell loss restricted to layer II in monkeys $\mathrm{H} 1$ and $\mathrm{H} 2$, a finding consistent with the slight and asymmetrical nature of the white matter damage observed in these $\mathrm{H}$ monkeys. Second, bilateral lesions of the fornix in monkeys (Zola Morgan et al., 1989a) cause a memory impairment that is similar to the level of memory impairment in the $\mathrm{H}$ monkeys. Lesions of the fornix produce no detectable cell loss in the entorhinal cortex. Third, ischemic lesions of the hippocampal region (the ISC lesion) cause a memory impairment that is similar to the impairment in the $\mathrm{H}$ monkeys (Zola-Morgan et al., 1994). Moreover, like the H monkeys, ISC monkeys performed better overall than the $\mathrm{H}^{+}$monkeys (Zola-Morgan et al., 1992). Quantitative neurohistological examination indicated that the ISC group had no detectable cell loss in the entorhinal cortex. Thus, it seems unlikely that memory impairment in the $\mathrm{H}$ animals was caused by retrograde degeneration in the entorhinal cortex.

Motor skill learning. Of the three $\mathrm{H}$ monkeys that were tested on the Lifesaver motor skill task, monkeys $\mathrm{H} 1$ and $\mathrm{H} 2$ had difficulty either learning $(\mathrm{H} 2)$ or retaining $(\mathrm{H} 1$ and $\mathrm{H} 2)$ the motor skill. A possible explanation is that these two monkeys sustained damage, albeit unilateral, to the caudate nucleus (severe In the case of monkey $\mathrm{H} 2$ and mild in the case of monkey $\mathrm{H} 1$ ). In rats (Packard et al., 1989) and monkeys (Wang et al., 1990) tasks of habit memory are impaired by caudate nucleus lesions. Neuropsychological studies have also suggested that the basal ganglia may be particularly important for motor skill learning (Heindel et al., 1989).

Summary. The findings reported here make two important points. First, the findings with $\mathrm{H}$ monkeys, like the findings from the ISC monkeys (Zola-Morgan et al., 1992), show that damage limited to the hippocampal region, even when incomplete, is sufficient to produce detectable memory impairment in monkeys. These findings correspond to previous findings in humans (patient R.B.) and rats (Mumby ct al., 1992; Wood et al., 1993) and emphasize the important contribution to memory made by the hippocampal region. Second, the $H$ monkeys were less impaired overall than monkeys with $\mathrm{H}^{+}$lesions. This finding, together with other recent findings (Meunier et al., 1993; Suzuki et al., 1993; Zola-Morgan et al., 1993) described above, emphasizes the importance for memory functions of the cortex adjacent to the hippocampal region.

\section{References}

Alvarez-Royo P, Clower RP, Zola-Morgan S, Squire LR (1991) Stereotaxic lesions of the hippocampus in monkeys: determination of surgical coordinates and analysis of lesions using magnetic resonance imaging. J Neurosci Methods 38:223-232.

Bachevalier J, Brickson M, Haggar C (1993) Limbic-dependent recognition memory in monkeys develops early in infancy. Neuroreport 4:77-80.

Beason-Held L, Rosene DL, Moss MR (1993) Memory deficits associated with ibotenic acid lesions of the hippocampal formation in rhesus monkeys. Soc Neurosci Abstr 23:438.

Bunsey M, Eichenbaum H (1993) Paired associate learning in rats: critical involvement of the parahippocampal region. Behav Neurosci 107:740-747.

Davis HP, Volpe B T (1990) Memory performance after ischemic or neurotoxic damage of the hippocampus. In: The biology of memory (Squire LR, Lindenlaub E, eds), pp 477-504. Stuttgart: Schattauer.

Eichenbaum H, Otto T, Cohen NJ (1992) The hippocampus-what does it do? Behav Neural Biol 57:2-36

Gaffan D (1974) Recognition impaired and association intact in the memory of monkeys after transection of the fornix. J Comp Physiol Psychol 86:1100-1109.

Gaffan D, Gaffan EA, Harrison S (1984) Effects of fornix transection on spontaneous non-matching by monkeys. Q J Exp Psychol 36B: 285-303.

Harlow H, Bromer JA (1938) A test-apparatus for monkeys. Psychol Rev 19:434-438.

Hartley LH, Roger R, Nicolosi RJ, Hartley T (1984) Blood pressure values in Macaca fascicularis. J Med Primatol 13:183-189.

Heindel WC, Salmon DP, Shults CW, Walicke PA, Butters N (1989) 
Neuropsychological evidence for multiple implicit memory systems: a comparison of Alzheimer's, Huntington's, and Parkinson's disease patients. J Neurosci 9:582-587.

Hutchins B, Weber JT (1983) A rapid myelin stain for frozen sections: modification of the Heidenhain procedure. J Neurosci Methods 7:289-294.

Insausti R, Amaral DG, Cowan WM (1987) The entorhinal cortex of the monkey. II. Cortical afferents. J Comp Neurol 264:356-395.

Jaffard R, Meunier M (1993) Role of the hippocampal formation in learning and memory. Hippocampus 3:203-218.

Jarrard LE (1993) On the role of the hippocampus in learning and memory in the rat. Behav Neurosci 60:9-26.

Johansen FF Zimmer J, Diemer NH (1987) Early loss of somatostatin neurons in dentate hilus after cerebral ischemia in the rat precedes CA-1 pyramidal cell loss. Acta Neuropathol (Berl) 73:110-114.

Leonard BW, Amaral DG, Zola-Morgan S, Squire LR (in press) Transient memory impairment in monkeys with bilateral lesions of the entorhinal cortex. J Neurosci, in press.

McKee RD, Squire LR (1993) On the development of declarative memory. J Exp Psychol [Mem Learn Cognit] 19:397-404.

Meunier M, Bachevalier J, Mishkin M, Murray EA (1993) Effects on visual recognition of combined and separate ablations of the entorhinal and perirhinal cortex in rhesus monkeys. J Neurosci 13:54185432

Mishkin M (1978) Memory in monkeys severely impaired by combined but not separate removal of the amygdala and hippocampus. Nature 273:297-298.

Mumby DG, Pinel JP (1994) Rhinal cortex lesions and object recognition in rats. Behav Neurosci 108:11-18

Mumby DG, Pinel JP, Kornecook TJ (1992) Dissociating the effects of hippocampal and amygdalar lesions in rats with a battery of nonspatial memory tasks. Soc Neurosci Abstr 18:1423.

Murray EA (1992) Medial temporal lobe structures contributing to recognition memory: the amygdaloid complex versus rhinal cortex. In: The amygdala: neurobiological aspects of emotion, memory, and mental dysfunction (Aggleton JP, ed), pp 453-470. London: WileyLiss.

Murray EA, Gaffan D (1993) Effects of lesions of rhinal cortex, hippocampus, or parahippocampal gyrus in rhesus monkeys on object and spatial rcversals. Soc Ncurosci Abstr 23:438.

Nadler JV, Evenson DA (1983) Use of excitatory amino acids to make axon-sparing lesions of hypothalamus. Methods Enzymol 103:393400 .

O'Boyle VJ Jr, Murray EA, Mishkin M (1993) Effects of excitotoxic amygdalo-hippocampal lesions on visual recognition in thesus monkeys. Soc Neurosci Abstr 23:438.

Otto T, Eichenbaum H (1992) Complementary roles of the orbital prefrontal cortex and the perirhinal-entorhinal cortices in an odor-guided delayed-nonmatching-to-sample task. Behav Neurosci 106:762-775.

Packard MG, Hirsh R, White NM (1989) Differential effects of fornix and caudate nucleus lesions on two radial maze tasks: evidence for multiple memory systems. J Neurosci 9:1465-1472.

Ringo JL (1988) Seemingly discrepant data from hippocampectomized macaques are reconciled by detectability analysis. Behav Neurosci 102:173-177.

Roberts WW, Dember WN, Brodwick M (1962) Alternation and exploration in rats with hippocampal lesions. J Comp Physiol Psychol $55: 695-700$
Squire LR, Zola-Morgan S (1991) The medial temporal lobe memory system. Science 253:1380-1386.

Suzuki W, Zola-Morgan S, Squire LR, Amaral DG (1993) Lesions of the perirhinal and parahippocampal cortices in the monkey produce longlasting memory impairment in the visual and tactual modalities. J Neurosci 13:2430-2451

Szabo J, Cowan WM (1984) A stereotaxic atlas of the brain of the cynomolgus monkey (Macaca fascicularis). J Comp Neurol 222: $265-300$.

Victor M, Agamanolis D (1990) Amnesia due to lesions confined to the hippocampus: a clinical-pathologic study. J Cognit Neurosci 2:246-257.

Wang J, Aigner T, Mishkin M (1990) Effects of neostriatal lesions on visual habit formation of rhesus monkeys. Soc Neurosci Abstr 16 : 617

Wood ER, Phillips $\Lambda G$ (1991) Deficits on a one trial object recognition task by rats with hippocampal CAl lesions produced by cerebral ischemia. Neurosci Res Commun 9:177-182.

Wood ER, Mumby DG, Pinel JP, Phillips AG (1993) Inpaired object recognition memory in rats following ischemia-induced damage to the hippocampus. Behav Neurosci 107:51-62.

Zola-Morgan S, Squire LR (1984) Preserved learning in monkeys with medial temporal lesions: sparing of motor and cognitive skills. J Neurosci 4:1072-1085.

Zola-Morgan S, Squire LR (1985) Medial temporal lesions in monkeys impair memory in a variety of tasks sensitive to human amnesia Behav Neurosci 99:22-34.

Zola-Morgan S, Squire LR (1986) Memory impairment in monkeys following lesions of the hippocampus. Behav Neurosci 100:165-170.

Zola-Morgan S, Squire LR (1993) Neuroanatomy of memory. Annu Rev Neurosci 16:547-563.

Zola-Morgan S, Squire LR, Amaral DG (1986) Human amnesia and the medial temporal region: enduring memory impairment following a bilateral lesion limited to field CAl of the hippocampus. J Neurosci 6:2950-2967.

Zola-Morgan S, Squire LR, Amaral DG (1989a) Lesions of the hippocampal formation but not lesions of the fornix or the mammillary nuclei produce long-lasting memory impairment in monkeys. J Neurosci 9:897-912.

Zola-Morgan S, Squire LR, Amaral DG (1989b) Lesions of the amygdala that spare adjacent cortical regions do not impair memory or exacerbate the impairment following lesions of the hippocampal formation. J Neurosci 9:1922-1936.

Zola-Morgan S, Squire LR, Amaral DG, Suzuki W (1989c) Lesions of perirhinal and parahippocampal cortex that spare the amygdala and hippocampal formation produce severe memory impairment. J Neurosci $9: 4355-4370$.

Zola-Morgan S, Squire LR, Alvarez-Royo P, Clower RP (1991) Independence of memory functions and emotional behavior: separate contributions of the hippocampal formation and the amygdala. Hippocampus 1:181-194.

Zola-Morgan S, Squire L, Rempel NL, Clower RP, Amaral DG (1992) Enduring memory impairment in monkeys after ischemic damage to the hippocampus. J Neurosci 12:2582-2596.

Zola-Morgan S, Squire L, Clower RP, Rempel NL (1993) Damage to the perirhinal cortex exacerbates memory impairment following lesions to the hippocampal formation. J Neurosci 13:251-265.

Zola-Morgan S, Squire LR, Ramus SJ (1994) Severity of memory impairment in monkcys as a function of locus and extent of damage within the medial temporal lobe memory system. Hippocampus 4:483-495. 